\title{
Only naughty the first time
}

On 21 September 1995, Canada's Tobacco Products Control Act, which banned tobacco advertising in 1988, was declared unconstitutional by its Supreme Court by the slimmest of margins (5 to 4 ). Within weeks of the decision, the Marquess of Queensberry rule book for tobacco advertising was torn up by the publication of advertisements for Buz cigarettes in a weekly entertainment newspaper in Vancouver, ironically named Terminal City. John Safran's accompanying report in this issue's Industry Watch (page 100) relates how, four years later, Philip Morris Australia purely coincidentally planned to name its video programme "The Buzz Team".

With its new found advertising freedom, the tobacco industry in Canada instantly dropped all pretence that it was not interested in targeting youth. No more need to astonish the rest of the business world with its oddball claims that unlike every other business, it was not interested in first time buyers and new customers. No more hand on heart that it never conducted market research with 14 year olds. No more travelling academic consultants with "proof" that tobacco advertising was irrelevant to aggregate demand.

The Canadian ad shows two naked girls, quite conceivably aged 13 or 14 years, on a dishevelled bed sharing a post-coital cigarette. Handcuffs, body piercing, tattoos, a mocking health warning ("Smoking will kill you"-not can or might), a reference to "industrial strength flavour" together with a gesture toward dilettante environmentalism ("no additives"), the visuals sit beneath an explicit illicit pleasure beckoning slogan "Catch a BUZ . . . it's only naughty the first time". By naming a brand with drug vernacular and flagrantly positioning cigarettes half way between dope and lesbianism, taking up smoking was never so promising.

For the major players in the world cigarette market the ad served two purposes. Marketed by a small US based firm, National Tobacco Corp, doing business as BUZ Canada Ltd, the ad was seen by Canadian health workers as a strategic ploy by the US industry to redefine rapidly the boundaries of the permissible by simply removing them. But just as importantly, it also would allow them to claim that their own advertising onslaught is a reluctant attempt to defend their cherished market shares, built up by the relatively restrained advertising of the past, from this new upstart entrant.

SIMON CHAPMAN Editor

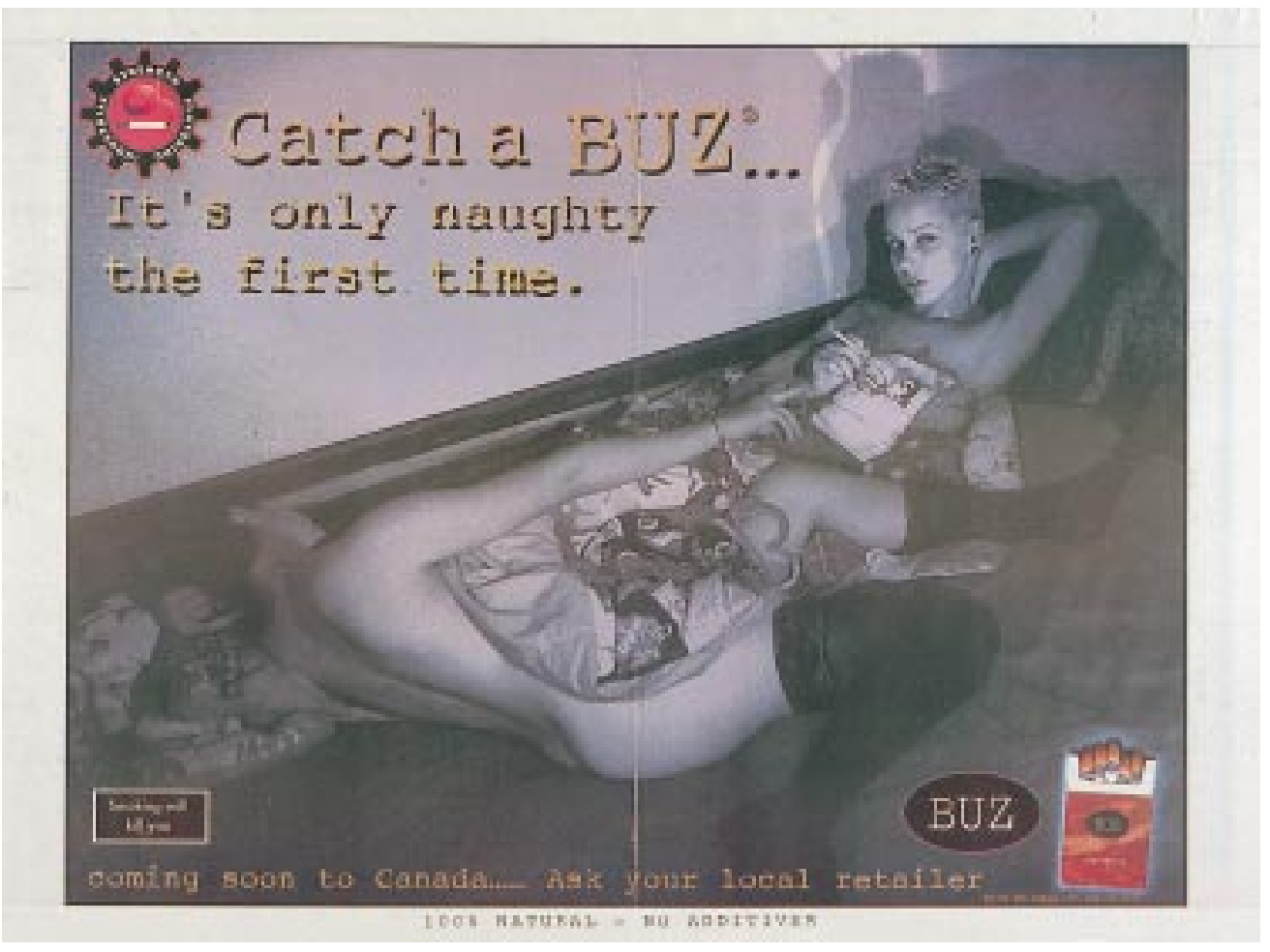

